\title{
Ivermectin as an inhibitor of cancer stem-like cells
}

\author{
GUADALUPE DOMINGUEZ-GOMEZ ${ }^{1 *}$, ALMA CHAVEZ-BLANCO ${ }^{1 *}$, JOSE LUIS MEDINA-FRANCO ${ }^{2}$, \\ FERNANDA SALDIVAR-GONZALEZ ${ }^{2}$, YTZEL FLORES-TORRONTEGUI ${ }^{1}{ }$, MANDY JUAREZ ${ }^{1}$, \\ JOSÉ DÍAZ-CHÁVEZ ${ }^{1}$, AURORA GONZALEZ-FIERRO ${ }^{1}$ and ALFONSO DUEÑAS-GONZÁLEZ ${ }^{3,4}$ \\ ${ }^{1}$ Division of Basic Research, National Cancer Institute Mexico, Mexico City 14080; \\ ${ }^{2}$ Faculty of Chemistry, Pharmacy Department, National Autonomous University of Mexico; \\ ${ }^{3}$ Unit of Biomedical Research in Cancer, Institute of Biomedical Research, National Autonomous University \\ of Mexico, Mexico City 04510; ${ }^{4}$ Unit of Biomedical Research in Cancer, \\ National Cancer Institute Mexico, Mexico City 14080, Mexico
}

Received December 23, 2016; Accepted August 7, 2017

DOI: $10.3892 / \mathrm{mmr} .2017 .8231$

\begin{abstract}
The aim of the present study was to demonstrate that ivermectin preferentially inhibited cancer stem-like cells (CSC) in breast cancer cells and downregulated the expression of 'stemness' genes. Computational searching of DrugBank, a database of approved drugs, was performed using the principles of two-dimensional similarity searching; the chemical structure of salinomycin was used as a query. Growth inhibition of the breast cancer cell lin e MDA-MB-231 by ivermectin was investigated in the total cell population, in cell spheroids and in sorted cells that expressed cluster of differentiation (CD) $44^{+} / \mathrm{CD} 24^{-}$. The effects of ivermectin treatment on the expression of pluripotency and self-renewal transcription factors, such as homeobox protein nanog (nanog), octamer-binding protein 4 (oct-4) and SRY-box 2 (sox-2), were evaluated by reverse transcription-quantitative polymerase chain reaction and western blotting. Ivermectin exhibited a similarity value of 0.78 in reference to salinomycin. Ivermectin demonstrated an inhibitory effect upon the growth of MDA-MB-231 cells in the range of 0.2-8 $\mu \mathrm{M}$. Ivermectin preferentially inhibits the viability of CSC-enriched populations $\left(\mathrm{CD} 44^{+} / \mathrm{CD} 24^{-}\right.$and cells growing in spheroids) compared with the total cell population. The opposite pattern was observed with paclitaxel treatment. Ivermectin exposure reduced the expression of nanog, oct- 4 and sox- 2 at the mRNA and protein levels. Ivermectin preferentially inhibited the CSC subpopulation in the MDA-MB-231 cells
\end{abstract}

Correspondence to: $\mathrm{Dr}$ Alfonso Dueñas-González, Unit of Biomedical Research in Cancer, National Cancer Institute Mexico, 22 San Fernando, Tlalpan, Mexico City 14080, Mexico

E-mail: alfonso_duenasg@yahoo.com

*Contributed equally

Key words: ivermectin, drug repositioning, cancer stem-like cells, breast cancer and downregulated the expression of genes involved in the maintenance of pluripotency and self-renewal.

\section{Introduction}

Ivermectin, a polycyclic lactone pesticide produced by bacterium Streptomyces avermitilis is a broad-spectrum antiparasitic drug that has been used in human medicine since 1987 (1). It is the drug of choice in treating onchocerciasis and strongyloidiasis, and as a therapeutic option for mass population treatment campaigns for lymphatic filariasis. As a microfilaricide, a single dose of ivermectin is fast, effective and well tolerated, and causes little to no severe inflammatory responses (2). Commonly observed adverse effects from treatment with ivermectin are mild and self-limiting and include: Skin reactions (such as itching), musculoskeletal pain, fever, swelling of the face, joints and limbs, headaches and dizziness, lymphadenopathy, eye reactions and pain from parasitic nodules (3).

Previous studies on the molecular pathogenesis of cancer has improved our knowledge and increased interest in repurposing non-cancer drugs to be used against this disease (4). A study from 1996 reported that ivermectin treatment in murine multidrug-resistant (MDR)-P388 and human MDR-CEM leukemia cells was a substrate and inhibitor of P-glycoprotein-mediated multidrug resistance in cancer (5). Another study demonstrated that ivermectin, at doses of 3-5 mg/kg, was able to suppress the growth of human melanoma and a number of other cancer xenografts in mice without adverse effects (6). In 2009, a high-throughput screen was performed to identify the selective inhibitors of cancer stem-like cells (CSCs) and demonstrated that salinomycin treatment reduced the proportion of CSCs by $>100$-fold relative to paclitaxel, inhibited mammary tumor growth in vivo and increased epithelial differentiation of tumor cells, accompanied by a loss of expression of breast CSC genes (7). As salinomycin is an antiparasitic drug for veterinary use only, similar compounds for human use were investigated that may also act as selective inhibitors of CSC. The results of the present study demonstrated that ivermectin exhibits a high degree of 
similarity with salinomycin and preferentially inhibited the CSC subpopulation in a breast cancer model.

\section{Materials and methods}

Computational searches. To systematically identify FDA approved drugs that exhibit similar activity as salinomycin, a fast computational search of the DrugBank database 4.0 of approved drugs was performed (8). Using the principles of similarity searching with two-dimensional fingerprints, the chemical structure of salinomycin was used as a query to compute the similarity of each of 1,623 compounds in DrugBank using the Molecular ACCess System keys (9) and the Tanimoto coefficient (10), as implemented in Molecular Operating Environment (version 2010.10) (11). The selection of hit compounds was based on similarity values and visual inspection.

Cell culture and drugs. The breast cancer cell line MDA-MB-231 was obtained from the American Type Culture Collection (Manassas, VA, USA). Cells were cultured in Dulbecco's modified Eagle's medium (DMEM)/F12 medium supplemented with $10 \%$ of fetal bovine serum (FBS) (both from Invitrogen; Thermo Fisher Scientific, Inc., Waltham, MA, USA) at $37^{\circ} \mathrm{C}$ in a humidified $5 \% \mathrm{CO}_{2}$ atmosphere. Ivermectin and paclitaxel were purchased from Sigma-Aldrich (Merck KGaA, Darmstadt, Germany).

Cell viability assay. Cells were seeded $\left(2 \times 10^{3}\right.$ cells/well) into 96-well microplates (Corning Incorporated, Corning, NY, USA) into $0.1 \mathrm{ml}$ of medium at $37^{\circ} \mathrm{C}$ for $24 \mathrm{~h}$, and then treated with either ivermectin $(0.2,0.4,0.8,1,5$ or $8 \mu \mathrm{M})$ or paclitaxel $(0.001$, $0.1,10$ or $1,000 \mathrm{nM}$ ) for $72 \mathrm{~h}$ at $37^{\circ} \mathrm{C}$. The medium was replaced with fresh medium containing drug or vehicle daily. Equal volumes of ethanol and DMSO vehicles were used for ivermectin and paclitaxel, respectively. Cell viability was evaluated by the colorimetric assay CellTiter 96 AQueous One Solution Cell Proliferation assay (Promega Corporation, Madison, WI, USA) according to the manufacturer's protocol. Following $72 \mathrm{~h}$ treatment, the AQueous One Solution reagent was added and incubated for an additional $4 \mathrm{~h}$ at $37^{\circ} \mathrm{C}$. The optical density was measured at $490 \mathrm{~nm}$, using a plate reader and the effect of each treatment was expressed as a percentage of cell viability relative to the untreated control cells. Mean values and standard deviations were calculated; experiments were performed in triplicate.

Clonogenic assay. MDA-MB-231 cells $\left(4.5 \times 10^{5}\right)$ were plated in a $25 \mathrm{~cm}^{2}$ cell culture flask and incubated for $48 \mathrm{~h}$ to allow the cells to proliferate to reach a cell density of $70 \%$. Cells were treated with different doses of ivermectin $(0.2,0.4,0.8,1,5$ and $8 \mu \mathrm{M})$ for $120 \mathrm{~h}$. Control cells were treated with the corresponding amounts of ethanol (the ivermectin vehicle). After $120 \mathrm{~h}$, cells were collected and cultured in drug-free medium in a dish ( $2 \mathrm{~mm}$ grid; 60x15 mm; Corning Incorporated) for 21 days. Subsequently, colonies were fixed in methanol and acetic acid $(3: 1 \mathrm{v} / \mathrm{v})$, and stained with $0.4 \%$ crystal violet (Sigma-Aldrich; Merck KGaA). The number of colonies on the culture dish were counted with a stereo microscope and quantified using ImageJ software version 1.50f (National Institutes of Health, Bethesda, MD, USA).
Spheroid culture. MDA-MB-231 cells $\left(4.5 \times 10^{5}\right)$ were grown in a $25 \mathrm{~cm}^{2}$ cell culture flask and incubated in DMEM/F12 medium, $10 \%$ fetal bovine serum, penicillin $(100 \mathrm{U} / \mathrm{ml})$ and streptomycin $(1.0 \mathrm{mg} / \mathrm{ml})$ at $37^{\circ} \mathrm{C}$ in humidified atmosphere of $5 \% \mathrm{CO}_{2}$ for $48 \mathrm{~h}$, to allow the cells to proliferate to a confluence of $\sim 80 \%$. Cells were collected and sub-cultured $\left(1 \times 10^{3}\right.$ cells) in 24 -well ultra-low attachment multiwell plates (Corning Costar; Corning Incorporated) for 15 days with $1 \mathrm{ml}$ MammoCult Basal Medium plus supplements (STEMCELL Technologies, Inc., Vancouver, BC, Canada), $0.48 \mu \mathrm{g} / \mathrm{ml}$ hydrocortisone and $4 \mu \mathrm{g} / \mathrm{ml}$ heparin, at $37^{\circ} \mathrm{C}$ in a humidified atmosphere of $5 \% \mathrm{CO}_{2}$ and $95 \%$ air. The medium was changed every 2 days. Following 15 days incubation, the spheroids (confluence, $\sim 60-70 \%$ ) were dispersed and stained with $0.4 \%$ trypan blue to assess the cell viability and counted with a TC10 Automated Cell Counter (Bio-Rad Laboratories, Inc., Hercules, CA, USA). Cells $\left(1 \times 10^{3}\right)$ were seeded into a 96-well plate and exposed to ivermectin $(0.25,0.5,1,2,4$ and $8 \mu \mathrm{M})$ or paclitaxel $(0.1,0.1,1,10$ and $100 \mathrm{nM})$ for $72 \mathrm{~h}$, or their respective vehicles, ethanol or DMSO.

Sorting the cluster of differentiation $(C D) 44^{+} / C D 24$ subpopulation of MDA-MB-231 cells by flow cytometry. MDA-MB-231 cells $\left(5 \times 10^{5}\right)$ were seeded in $75 \mathrm{~cm}^{2}$ culture flasks and incubated in complete medium for $48 \mathrm{~h}$ to achieve a confluence of $\sim 90 \%$. Cells were washed once with PBS and then harvested with $0.05 \%$ trypsin $+0.025 \%$ EDTA. Detached cells were washed with blocking reagent (1\% FBS in PBS) and resuspended in $1 \mathrm{ml}$ wash buffer $\left(1 \times 10^{6}\right.$ cells $\left./ 100 \mu \mathrm{l}\right)$, containing the fluorophore-conjugated monoclonal antibodies against CD44 (fluorescein isothiocyanate-conjugated; catalog no. 555742; BD Biosciences, Franklin Lakes, NJ, USA) and against human CD24 (phycoerythrin-conjugated; catalog no. 311106; BioLegend, Inc., San Diego, CA, USA)

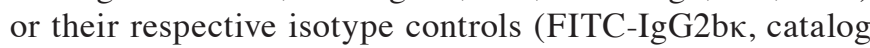
no. 555742; PE-IgG2aк, catalog no. 555574; BD Biosciences). Antibodies were used at the manufacturer's recommended concentrations (dilution: $20 \mu \mathrm{g} / 1 \times 10^{6}$ cells in $100 \mu \mathrm{l}$ ) and incubated at $4^{\circ} \mathrm{C}$ in the dark for $40 \mathrm{~min}$. Labeled cells were washed in the wash buffer twice. The stem cell marker profiling analysis was performed using a BD FACScanto II (BD Biosciences). Live cell sorting was performed using a BD FACSAria (BD Biosciences). The percentage of cells in different marker populations was evaluated using BD FACSDiva version 6.1.3 (BD Biosciences). The sorted cells were resuspended three times in DMEM-F12-10\% FBS with $10,000 \mathrm{U} / \mathrm{ml}$ penicillin, $10 \mathrm{mg} / \mathrm{ml}$ streptomycin and $0.025 \mathrm{mg} / \mathrm{ml}$ amphotericin B. Cells were counted using the trypan blue method and seeded $\left(1 \times 10^{3}\right.$ cells/well) in a 96-well plate with an ultra-low attachment surface (Corning-Costar; Corning Inc.) in Human MammoCult ${ }^{\mathrm{TM}}$ Proliferation supplement (STEMCELL Technologies, Inc.), $0.48 \mu \mathrm{g} / \mathrm{ml}$ hydrocortisone and $4 \mu \mathrm{g} / \mathrm{ml}$ heparin, for $24 \mathrm{~h}$ at $37^{\circ} \mathrm{C}$ in humidified atmosphere of $5 \% \mathrm{CO}_{2}$. Cells were treated with ivermectin $(0.25,0.5,1,2,4$ or $8 \mu \mathrm{M})$ or paclitaxel $(0.1,0.1$, 1,10 or $100 \mathrm{nM}$ ) or their respective vehicle controls for $72 \mathrm{~h}$. Finally, cells were stained with $0.4 \%$ trypan blue to assess cell viability and counted with TC10 Automated Cell Counter (Bio-Rad Laboratories, Inc., Hercules, CA, USA) as aforementioned. 
Expression of stemness genes by reverse transcription-quantitative polymerase chain reaction $(R T-q P C R)$. Unsorted, whole population MDA-MB-231 cells were treated with ivermectin for $72 \mathrm{~h}$ and total RNA was isolated when cells reached $\sim 70 \%$ confluence, using TRIzol reagent (Gibco; Thermo Fisher Scientific, Inc.) according to the manufacturer's protocol. RNA purity and integrity were assessed by spectrophotometric analysis using a NanoDrop 2000c (Thermo Fisher Scientific, Inc.) and denaturing 2\% agarose gel; bands were visualized using a MiniBIS Pro D-Transilluminator (DNR Bio-Imaging Systems Ltd., Neve Yamin, Israel).

A total of $1 \mu \mathrm{g}$ total RNA was used for cDNA synthesis with the GeneAmp RNA PCR Core kit (Applied Biosystems; Thermo Fisher Scientific, Inc.). cDNA was used with iQ SYBR Green SuperMix (Bio-Rad Laboratories, Inc.), according to the manufacturer's protocol. qPCR reactions were run in triplicate using an ABI Prism 7000 (Applied Biosystems; Thermo Fisher Scientific, Inc.). The qPCR cycling conditions were as follows: $10 \mathrm{~min}$ at $95^{\circ} \mathrm{C} ; 40$ cycles of $30 \mathrm{sec}$ at $95^{\circ} \mathrm{C}, 30 \mathrm{sec}$ at $60^{\circ} \mathrm{C}$ and $30 \mathrm{sec}$ at $72^{\circ} \mathrm{C}$. Data were analyzed using the $2^{-\Delta \Delta \mathrm{Cq}}$ method (12), and reported as the fold-change in gene expression normalized to the endogenous control gene hypoxanthine phosphoribosyltransferase 1 (HPRT1), and relative to cells without treatment. The primers used were: HPRT1 forward, 5'-GAACCTCTC GGCTTTCCCG-3' and reverse, 3'-CACTAATCACGACGC CAGGG-5'; homeobox protein nanog (nanog) forward, 5'-ACC TCGCTGATTAGGCTCCAA-3' and reverse, 3'-AGTCTG GACACTGGCTAATCC-5'; octamer binding protein 4 (oct-4) forward, 5'-CAGGCCCGAAAGAGAAAGC-3' and reverse, 3'-CCACACTCGGACCACATCCT-5'; and sox-2 forward, 5'-GCTAGTCTCCAAGCGACGAAA-3' and reverse, 3'-AAT TCAGCAAGAAGCCTCTCCTT-5'. The annealing temperature was $60^{\circ} \mathrm{C}$ for all reactions.

Protein extraction and western blot analysis of nanog, sox-2 and oct-4. Unsorted whole population MDA-MB-231 cells $\left(4 \times 10^{5}\right)$ were cultured in $25 \mathrm{~cm}^{2}$ flasks and treated with ivermectin (or its vehicle control) for $72 \mathrm{~h}$. Once the cells had reached a density of $\sim 70 \%$, the cells were washed once with PBS and then harvested with $0.05 \%$ trypsin $/ 0.025 \%$ EDTA. Detached cells were washed with PBS, proteins were extracted with radioimmunoprecipitation buffer $(150 \mathrm{mM} \mathrm{NaCl} ; 1.0 \%$ IGEPAL CA-630; $0.5 \%$ sodium deoxycholate; $0.1 \%$ SDS; $50 \mathrm{mM}$ Tris, $\mathrm{pH}$ 8.0) in the presence of proteinase inhibitors (catalog no. p8340; Sigma-Aldrich; Merck KGaA). Protein concentration was determined using a bicinchoninic acid assay and the integrity was assessed by coomassie staining. A total of $30 \mu \mathrm{g}$ protein was separated by $10 \%$ SDS-PAGE and transferred onto a polyvinylidene difluoride membrane (cat no. 162-0177; Bio-Rad Laboratories, Inc.). The membrane was blocked with $3 \%$ skim milk in PBS for $1 \mathrm{~h}$ at room temperature and subsequently incubated with antibodies against nanog (catalog no. sc-134218; 1:500); sox-2 (catalog no. sc-17320; 1:200); oct-4 (catalog no. sc-9081; 1:200) (all from Santa Cruz Biotechnology, Inc., Dallas, TX, USA), and anti-actin peroxidase (A3854; 1:10,000; Sigma-Aldrich; Merck $\mathrm{KGaA}$ ) in blocking solution (5\% skim milk in TBS + $0.1 \%$ Tween-20), overnight at $4^{\circ} \mathrm{C}$. The following secondary antibodies were used: Oct4, bovine anti-rabbit, sc-2370; sox-2, donkey anti-goat, sc-2020; nanog, anti-mouse, sc-2371 (all from Santa Cruz Biotechnology, Inc). Secondary antibodies were diluted 1:1,000 and the incubation was performed for $1 \mathrm{~h}$ at room temperature. Protein bands were visualized using the chromogenic substrate Clarity Western Enhanced Chemiluminescence Substrate (catalog no. 1705060; Bio-Rad Laboratories, Inc.). Bands were quantified densitometrically using Image $\mathrm{J}$ version 1.50f (National Institutes of Health, Bethesda, MD, USA).

Statistical analyses. Analyses were performed with GraphPad Prism software (version 6.0; GraphPad Software, Inc., La Jolla, CA, USA). The experiments were conducted with at least three independent triplicates. P-values were calculated using the one-way analysis of variance test followed by the Bonferroni post-hoc test. $\mathrm{P}<0.01$ was considered to indicate a statistically significant difference.

\section{Results}

Ivermectin exhibits high structural similarity to salinomycin. Compounds identified in DrugBank possessed a low molecular similarity with salinomycin (median and mean similarity values of $0.34 \pm 0.14$ ). Subsequent results from the similarity searching using salinomycin as a query molecule identified 25 top-ranked compounds with a high similarity value. To define a compound with 'high' similarity value, molecules were selected as those with similarity values two standard deviations above the mean similarity of all DrugBank compounds to salinomycin. Following visual inspection of the chemical structures of the identified compounds, the drugs with the highest similarity scores were ivermectin followed by natamycin (a food preservative) and narasin (an antibiotic for veterinary use). Ivermectin had the highest similarity value of 0.78 , and following the principle of molecular similarity, which states that similar compounds demonstrate similar properties (13) (with the exception of the so-called activity cliffs) (14), it was hypothesized that the antiparasitic drug ivermectin may also possess similar biological properties as salinomycin. In addition, ivermectin is a Food and Drug Administration (FDA)-approved drug for clinical use, whereas natamycin and narasin are not. Notably, using this method of screening that is based on structural similarity rather than biological activity upon CSC cells, as reported by Gupta et al (7), did not identify avermectin as a candidate compound. Two- and three-dimensional structures of salinomycin and ivermectin are provided in Fig. 1.

Ivermectin partially inhibits cell viability and clonogenic capacity. To evaluate the antitumoral effects of ivermectin on MDA-MB-231 cells, cell viability and clonogenicity was evaluated. A mild-to-moderate dose-dependent effect was observed in cells treated with various concentrations of ivermectin (Fig. 2A); however, cell viability did not decrease beyond $45 \%$, even at $8 \mu \mathrm{M}$ of ivermectin. Statistically significant differences were observed at concentrations between 0.8 and $8 \mu \mathrm{M}$, compared with untreated controls $(\mathrm{P}<0.0001)$. Colony forming ability was also significantly reduced with ivermectin treatment with doses as low as $0.2 \mu \mathrm{M}$ (Fig. 2B); however, these effects appear to be similar at doses between 1 and $8 \mu \mathrm{M}(\mathrm{P}<0.0001)$. 

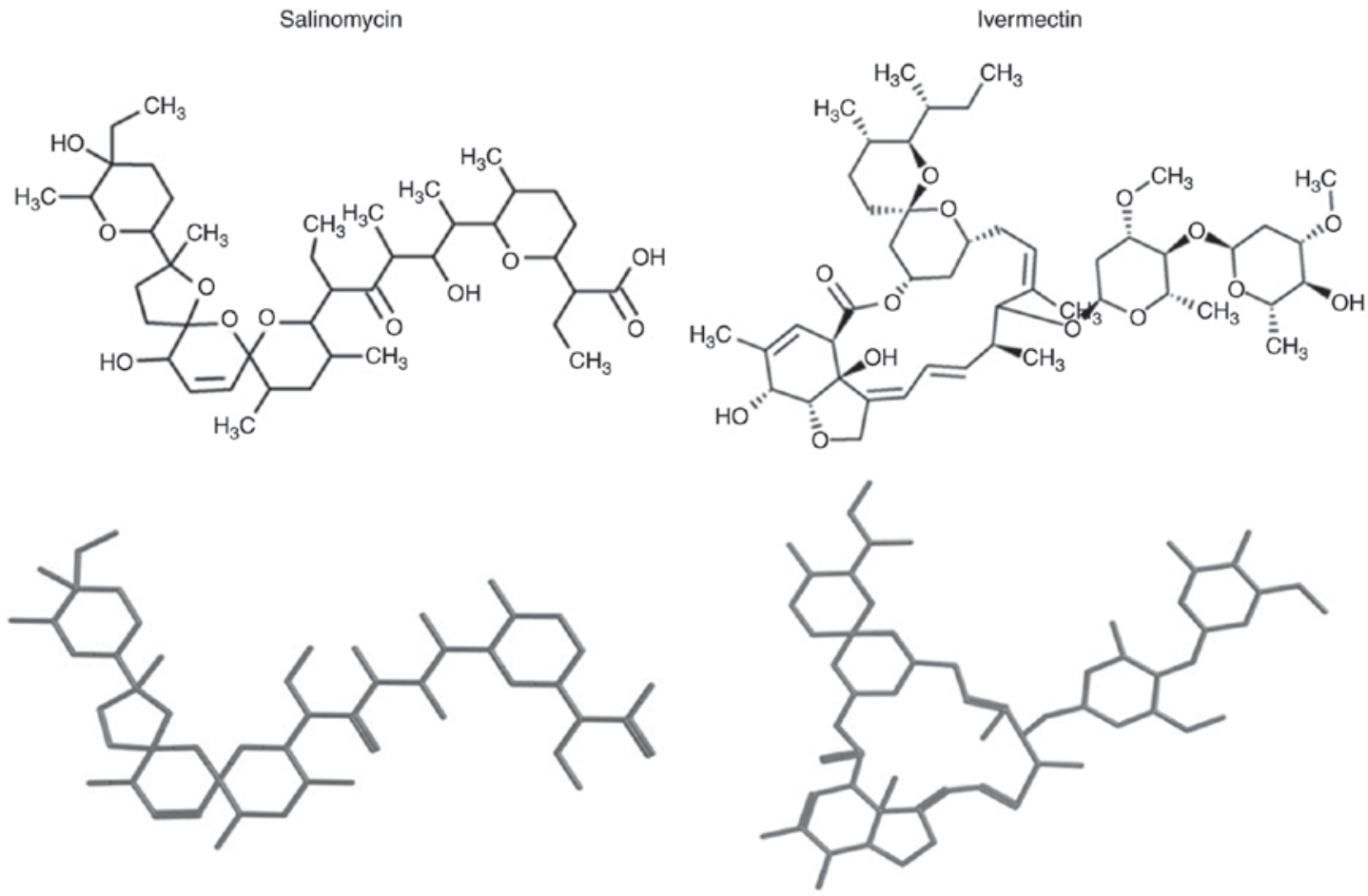

Figure 1. Chemical structures of ivermectin and salinomycin. Two-dimensional (upper panels) and three-dimensional (lower panels) representations of the chemical structures of salinomycin and ivermectin.

A

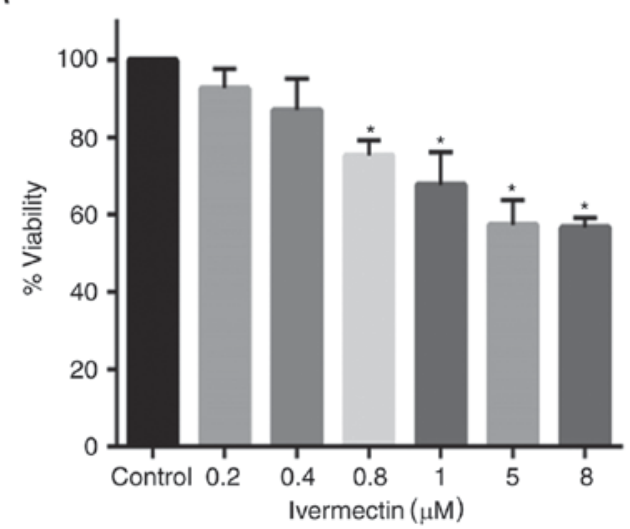

B

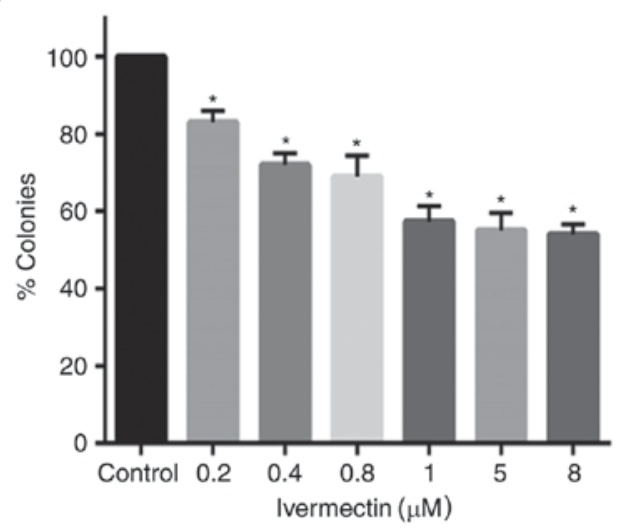

Figure 2. Inhibitory effects of ivermectin on MDA-MB-231 cell viability. (A) Analysis of the effects of ivermectin treatment $(0.2,0.4,0.8,1,5$ and $8 \mu \mathrm{M})$ on cell viability. (B) Effects of ivermectin treatment $(0.2,0.4,0.8,1,5$ and $8 \mu \mathrm{M})$ on clonogenicity. ${ }^{*} \mathrm{P}<0.0001$ vs. control.

Inhibitory effects of ivermectin and paclitaxel in stem cell enriched MDA-MB-231 cells. The $\mathrm{CD} 44^{+} / \mathrm{CD} 24^{-}$subpopulation of MDA-MB-231 cells has been previously reported to possess stem/progenitor cell properties, and this subpopulation in patients with breast cancer exclusively retains the ability to form novel tumors in a non-obese diabetic-severe compromised immunodeficiency mouse xenograft model $(15,16)$. The proportion of $\mathrm{CD} 44^{+} / \mathrm{CD} 24^{-}$cells in the cell line MDA-MB-231 is $85 \pm 5 \%$ (17). In addition, spheroids of cell lines growing in nonadherent conditions are also reported to be enriched in stem cells (18). Therefore, these two conditions were used to determine whether ivermectin treatment preferentially inhibited the CSC population compared with treatments with the cytotoxic drug paclitaxel.
At concentrations $\leq 2 \mu \mathrm{M}$ ivermectin, there were no significant differences in viability in the total MDA-MB-231 population compared with cultures of cells grown in spheroids and those sorted by $\mathrm{CD} 44^{+} / \mathrm{CD} 24^{-}$(Fig. 3A). However, cells treated with 4 or $8 \mu \mathrm{M}$ ivermectin exhibited a significant decrease in viability in the CSC-enriched populations compared with the total cell population $(\mathrm{P}<0.001)$; whereas viability in the total cell population was inhibited by $\leq 30 \%$. As expected, the two subpopulations (spheroids and $\mathrm{CD} 44^{+} / \mathrm{CD} 24^{-}$) exhibited less inhibition with paclitaxel treatments compared with ivermectin treatments, and no significant differences were identified between either of these groups compared with the inhibition exhibited in the total MDA-MB-231 cell population (Fig. 3B). Ivermectin treatment exhibited an increased 
A

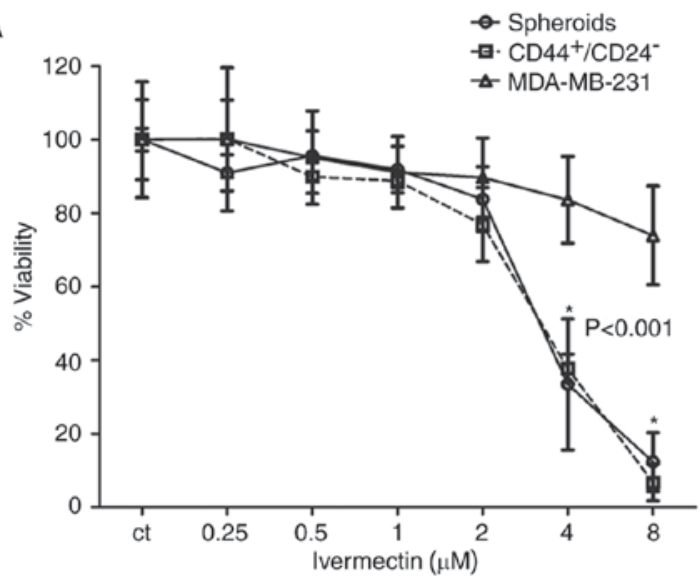

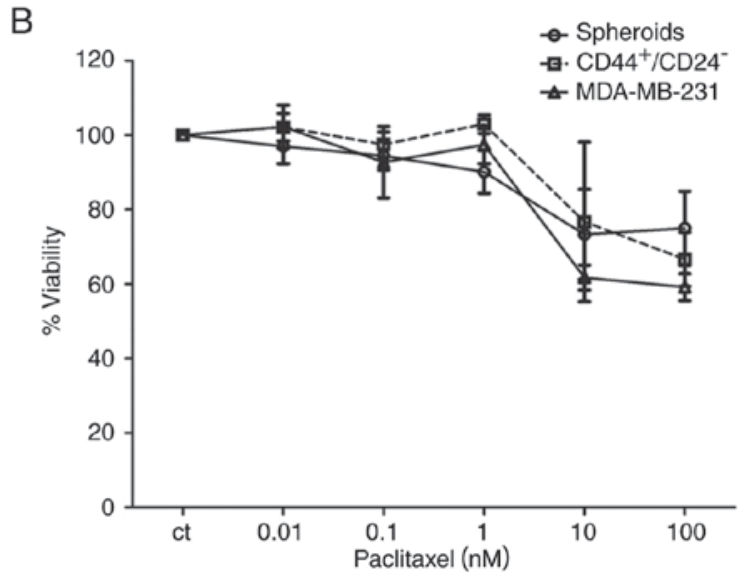

Figure 3. Effects of treatment with ivermectin or paclitaxel on the CSC-enriched populations of MDA-MB-231 cells. (A) The effect of ivermectin (0.25, $0.5,1,2,4$ and $8 \mu \mathrm{M}$ ) on cell viability of spheroids, CD44 ${ }^{+} \mathrm{CD} 24-$ selected and total MDA-MB-231 cells. A statistically significant effect of ivermectin was observed in the CSC-enriched populations at 4 and $8 \mu \mathrm{M}$ compared with the total MDA-MB-231 cell population. (B) The effects of paclitaxel ( $0.01,0.1,1,10$ and $100 \mathrm{nM}$ ) on cell viability of spheroids, $\mathrm{CD}_{4} 4^{+} / \mathrm{CD} 24$ selected and total MDA-MB-231 cells. No statistically significant differences were observed among the paclitaxel treatments. $\mathrm{CD}$, cluster of differentiation.
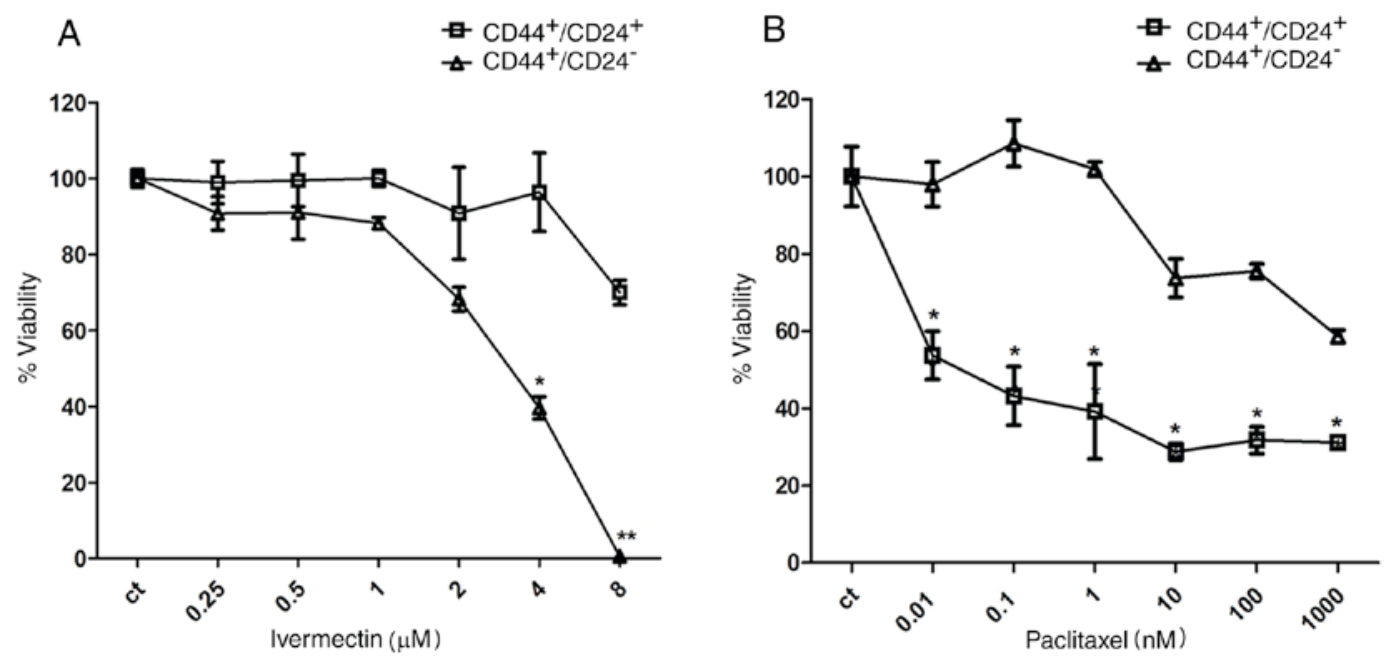

Figure 4. Effects of ivermectin treatment on $\mathrm{CD} 44^{+} / \mathrm{CD} 24{ }^{-}$and $\mathrm{CD} 44^{+} / \mathrm{CD} 24^{+} \mathrm{MDA}-\mathrm{MB}-231$ cells. (A) Effects of ivermectin treatment $(0.25,0.5,1,2,4$ and $8 \mu \mathrm{M})$ on cell viability of $\mathrm{CD} 44^{+} / \mathrm{CD} 24^{-}$and $\mathrm{CD} 44^{+} / \mathrm{CD} 24^{+} \mathrm{MDA}-\mathrm{MB}-231$ cells. A statistically significant effect of ivermectin was observed in CD44 $4^{+} / \mathrm{CD} 24$ cells at 4 and $8 \mu \mathrm{M}$, compared with $\mathrm{CD} 44^{+} / \mathrm{CD} 24^{-}$cells. (B) Effects of paclitaxel $\left(0.01,0.1,1,10,100\right.$ and 1,000 nM) on cell viability of CD44 ${ }^{+} / \mathrm{CD} 24^{-}$and $\mathrm{CD} 44^{+} / \mathrm{CD} 24^{+}$MDA-MB-231 cells. The opposite pattern was observed with paclitaxel at all concentrations tested ${ }^{*} \mathrm{P}<0.01$ and ${ }^{* *} \mathrm{P}<0.001 \mathrm{vs}$. CD $44^{+} / \mathrm{CD} 24^{+}$ cells. CD, cluster of differentiation.

inhibitory effect upon CSC-enriched subpopulations compared with cells treated with paclitaxel.

To further evaluate the relative selectivity of ivermectin upon the stem cell population, $\mathrm{CD} 44^{+} / \mathrm{CD} 24^{-}$and $\mathrm{CD} 44^{+} / \mathrm{CD} 24^{+}$ subpopulations of MDA-MB-231 cells were sorted and cultured in the presence of either ivermectin or paclitaxel. Cells treated with 4 and $8 \mu \mathrm{M}$ ivermectin exhibited a significant reduction in viability of the $\mathrm{CD} 44^{+} / \mathrm{CD} 24^{-}$stem cell population; $8 \mu \mathrm{M}$ ivermectin treatment reduced the $\mathrm{CD} 44^{+} / \mathrm{CD} 24^{-}$viability to $0 \%$, compared with $\mathrm{CD} 44^{+} / \mathrm{CD} 24^{+}$cells (Fig. $4 \mathrm{~A}$ ), whereas the reduction in viability in $\mathrm{CD} 44^{+} / \mathrm{CD} 24^{+}$cells treated with $8 \mu \mathrm{M}$ ivermectin approached $25 \%$. The non-CSC CD $44^{+} / \mathrm{CD} 24^{+}$ cell populations were sensitive to paclitaxel from $0.01 \mathrm{nM}$; whereas inhibition of the $\mathrm{CD} 44^{+} / \mathrm{CD} 24^{-}$stem cell subpopulation was only observed at $\geq 10 \mathrm{nM}$. Statistical differences were observed at all concentrations between $\mathrm{CD} 44^{+} / \mathrm{CD} 24^{+}$and CD44 ${ }^{+}$CD24-(Fig. 4B).
Ivermectin reduces the expression of stemness genes. As salinomycin has been demonstrated to decrease the expression of stemness genes including nanog (19), MDA-MB-231 cells cultured in normal (adherent) conditions were treated with ivermectin at $4 \mu \mathrm{M}$ for $72 \mathrm{~h}$ and the mRNA expression levels of nanog, sox- 2 and oct- 4 were evaluated by RT-qPCR and western blotting. As demonstrated in Fig. 5, ivermectin significantly reduced the expression of these three genes at both the mRNA and the protein level $(\mathrm{P}<0.01)$.

\section{Discussion}

In the field of drug repurposing for cancer therapy, major efforts have been undertaken to identify drugs that may selectively or preferentially target the CSC population of tumors. The results of the present study demonstrated that ivermectin, an antiparasitic drug for approved for human use, preferentially 

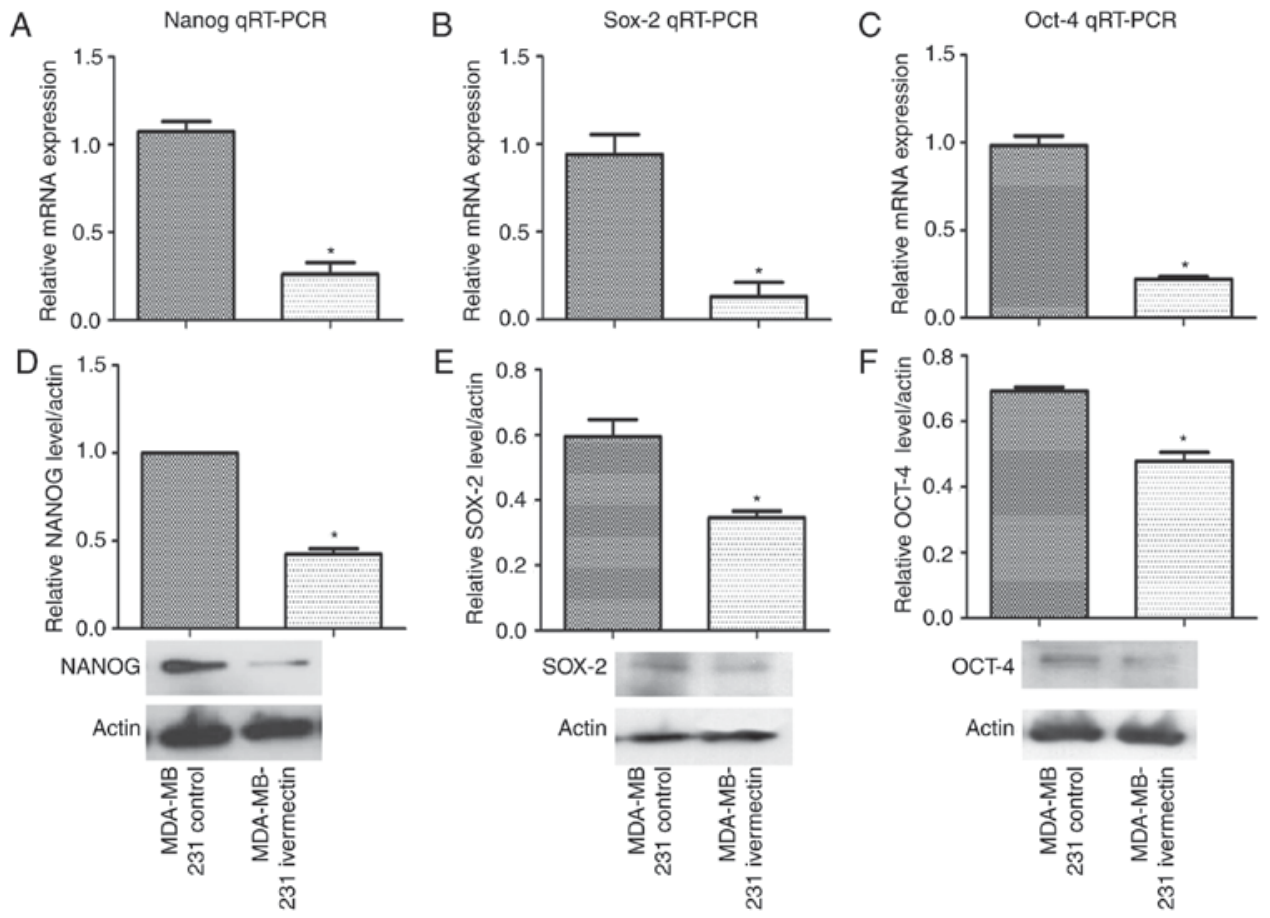

Figure 5. Stemness gene mRNA and protein expression levels are reduced following ivermectin treatment. (A-C) Relative mRNA expression levels of (A) nanog, (B) sox-2 and (C) oct-4. (D-F) Western blot analysis and quantified protein expression levels of (D) nanog, (E) sox-2 and (F) oct-4. "P<0.01 vs. control. Oct-4, octamer-binding protein 4; nanog, homeobox protein nanog; sox-2, transcription factor sox-2.

targeted the CSC-enriched subpopulation of the breast cancer cell line MDA-MB-231. Higher reductions in cell viability were observed for the $\mathrm{CD} 44^{+} / \mathrm{CD} 24^{-}$subpopulation and spheroids treated with ivermectin compared with paclitaxel. These results were accompanied by the decreased expression of stemness genes nanog, sox-2 and oct-4, previously reported to be highly expressed in CSCs (20).

Failure to successfully eradicate tumors no longer amenable to local treatments is at least partly due to the existence of CSCs, which are characterized by tumorigenic properties, such as self-renewal, formation of differentiated progeny and development of resistance to therapy (21). It has been established that Notch, hedgehog $(\mathrm{Hh})$ and Wnt signaling pathways are involved in the regulation of proliferation and differentiation of CSCs; therefore, these pathways may be key targets for the development of more efficient cancer therapeutics (22). However, the development of drugs that target crucial steps in the Wnt, Notch and Hh signaling pathways may not be effective or can be toxic, owing to the signaling crosstalk among these pathways. An alternative strategy may be to look in an unbiased and systematic manner at pharmacological entities that demonstrate preferential toxicity in CSCs over the total tumoral cell population $(7,23)$. A previous study performed a screen for agents with epithelial CSC-specific toxicity and identified four compounds that consistently reduced the proportion of CSCs, including salinomycin, etoposide, abamectin and nigericin (7). Among these, salinomycin was the most effective, exhibiting a $>100$-fold reduction in viability compared with paclitaxel. Further investigation demonstrated that salinomycin inhibited mammary tumor growth in vivo and induced an increase in epithelial differentiation of tumor cells, which is associated with the loss of stemness genes (7). That salinomycin is currently only approved for veterinary use, prompted the authors of the present study to search for drugs approved for human use by screening DrugBank to identify structurally similar, clinically approved drugs. The results of the present study adhered to the principle of molecular similarity that states that similar compounds demonstrate similar properties $(13,14)$; therefore, the antiparasitic drug ivermectin should exhibit similar biological effects to those reported for salinomycin $(7,24,25)$. This is advantageous in terms of drug repositioning, as the clinical use of ivermectin as antiparasitic is extensive (25), therefore, clinical trials in cancer may proceed in the near future.

Avermectins are 16-membered pentacyclic lactone compounds that are derived from polyketides and are linked to a disaccharide of the methylated deoxysugar L-oleandrose (26). Ivermectin was FDA-approved for human use in 1987 (http:// www.centerwatch.com/drug-information/fda-approved-drugs/ drug/250/stromectol-ivermectin), and is an avermectin derivative of major interest as a parasitic drug, and is a mixture of $80 \%$ 22,23-dihydro-avermectin-B1a and $20 \%$ of the -B1b homolog (27). As ivermectin is an ionophore, it induces chloride-dependent membrane hyperpolarization and apoptosis in leukemia (28) and induces mitochondrial dysfunction and oxidative stress (29). The antitumor effects of ivermectin have also been associated with its ability to inactivate the p21-activated kinase 1/protein kinase B axis, inducing cytostatic autophagy and modulation of $\mathrm{P} 2 \mathrm{X}$ purinoceptor (P2X) 4/P2X7/Pannexin-1 sensitivity to extracellular adenosine triphosphate $(30,31)$. Ivermectin was first investigated as an antitumor drug in 1999 (32) and, to the best of the of our knowledge, no studies have been performed on its ability to preferentially target CSCs. A previous study demonstrated that ivermectin treatment inhibits the Wnt-transcription factor 4 signaling pathway (33), which is frequently considered to be altered in CSCs (21). Recently, it was demonstrated that ivermectin downregulated 
the expression of stemness genes nanog and sox 2 , in addition to reducing the activity of aldehyde dehydrogenase, all of which are CSC markers (34). The results of the present study demonstrated preferential inhibition of CSC-enriched MDA-MB-231 cells treated with ivermectin, which agreed with the literature on the effects of ivermectin upon pathways and markers associated with CSCs. The present study, however, was not mechanistic; therefore, further investigations into the molecular basis responsible for the preferential cytotoxicity of ivermectin on CSCs must be pursued.

In conclusion, results from the present study demonstrated that ivermectin preferentially targeted the stem cell population in MDA-MB-231 human breast cancer cells. Ivermectin has been demonstrated to be safe, following treatment of millions of patients with onchocerciasis and other parasitic diseases, which makes it a strong candidate for further studies investigating its potential use as a repurposed drug for cancer therapy.

\section{Acknowledgements}

The present study was supported by FONSEC, National Council of Science and Technology, Mexico (grant no. 161915) and National Autonomous University of Mexico, Support Program for Research Projects on Science and Innovation (grant no. IT206611).

\section{References}

1. Stromectol cleared by the U.S. Food and Drug Administration to treat onchocerciasis. http://www.centerwatch.com/drug-information/fda-approved-drugs/drug/250/stromectol-ivermectin

2. Diawara L, Traoré MO, Badji A, Bissan Y, Doumbia K, Goita SF, KonatéL,MounkoroK,SarrMD,SeckAF,etal:Feasibilityofonchocerciasis elimination with ivermectin treatment in endemic foci in Africa: First evidence from studies in Mali and Senegal. PLoS Negl Trop Dis 3: e497, 2009.

3. Ottesen EA and Campbell WC: Ivermectin in human medicine. J Antimicrob Chemother 34: 195-203, 1994.

4. Dueñas-González A, García-López P, Herrera LA, Medina-Franco JL, González-Fierro A and Candelaria M: The prince and the pauper. A tale of anticancer targeted agents. Mol Cancer 7: 82, 2008

5. Didier A and Loor F: The abamectin derivative ivermectin is a potent P-glycoprotein inhibitor. Anticancer Drugs 7: 745-751, 1996

6. Driniaev VA, Mosin VA, Krugliak EB, Sterlina TC, Novik TC, Ermakova NV, Kublik LN, Levitman MKh, Shaposhnikova VV and Korystov IuN: Modification of antitumor effect of vincristine by natural avermectins. Antibiot Khimioter 49: 3-5, 2004 (In Russian).

7. Gupta PB, Onder TT, Jiang G, Tao K, Kuperwasser C, Weinberg RA and Lander ES: Identification of selective inhibitors of cancer stem cells by high-throughput screening. Cell 138: 645-659, 2009

8. Law V, Knox C, Djoumbou Y, Jewison T, Guo AC, Liu Y, Maciejewski A, Arndt D, Wilson M, Neveu V, et al: Drugbank 4.0: Shedding new light on drug metabolism. Nucl Acids Res 42 (Database Issue): D1091-D1097, 2014.

9. Durant JL, Leland BA, Henry DR and Nourse JG: Reoptimization of Mdl Keys for use in drug discovery. J Chem Inf Comput Sci 42: 1273-1280, 2002.

10. Willett P, Barnard JM and Downs GM: Chemical similarity searching. J Chem Inf Comput Sci 38: 983-996, 1998.

11. Molecular Operating Environment (MOE), version 2010.10. Chemical Computing Group Inc., Montreal, PQ, Canada. Available at: http://www.chemcomp.com.

12. Livak KJ and Schmittgen TD: Analysis of relative gene expression data using real-time quantitative PCR and the 2(-Delta Delta C(T)) method. Methods 25: 402-408, 2001.

13. Medina-Franco JL and Maggiora GM: Molecular similarity analysis. In: Chemoinformatics for Drug Discovery. Bajorath J (Ed). John Wiley \& Sons, Inc., Hoboken, New Jersey, pp343-399, 2014.
14. Maggiora GM: On outliers and activity cliffs - why QSAR often disappoints. J Chem Inf Model 46: 1535, 2006.

15. Tanaka H, Nakamura M, Kameda C, Kubo M, Sato N, Kuroki S, Tanaka M and Katano M: The Hedgehog signaling pathway plays an essential role in maintaining the $\mathrm{CD} 44^{+} \mathrm{CD} 24$-/low subpopulation and the side population of breast cancer cells. Anticancer Res 29: 2147-2157, 2009.

16. Al-Hajj M, Wicha MS, Benito-Hernandez A, Morrison SJ and Clarke MF: Prospective identification of tumorigenic breast cancer cells. Proc Natl Acad Sci USA 100: 3983-3988, 2003.

17. Sheridan C, Kishimoto H, Fuchs RK, Mehrotra S, Bhat-Nakshatri P, Turner $\mathrm{CH}$, Goulet R Jr, Badve $\mathrm{S}$ and Nakshatri H: CD $44^{+} / \mathrm{CD} 24^{-}$breast cancer cells exhibit enhanced invasive properties: An early step necessary for metastasis. Breast Cancer Res 8: R59, 2006.

18. Piscitelli E, Cocola C, Thaden FR, Pelucchi P, Gray B, Bertalot G, Albertini A, Reinbold R and Zucchi I: Culture and characterization of mammary cancer stem cells in mammospheres. Methods Mol Biol 1235: 243-262, 2015.

19. Wang Y: Effects of salinomycin on cancer stem cell in human lung adenocarcinoma A549 cells. Med Chem 7: 106-111, 2011.

20. Zhang W, Sui Y, Ni J and Yang T: Insights into the Nanog gene: A propeller for stemness in primitive stem cells. Int J Biol Sci 12: 1372-1381, 2016.

21. Dragu DL, Necula LG, Bleotu C, Diaconu CC and Chivu-Economescu M: Therapies targeting cancer stem cells: Current trends and future challenges. World J Stem Cells 7: 1185-1201, 2015.

22. Takebe N, Harris PJ, Warren RQ and Ivy PS: Targeting cancer stem cells by inhibiting Wnt, Notch, and Hedgehog pathways. Nat Rev Clin Oncol 8: 97-106, 2011.

23. Subedi A, Futamura Y, Nishi M, Ryo A, Watanabe N and Osada H: High-throughput screening identifies artesunate as selective inhibitor of cancer stemness: Involvement of mitochondrial metabolism. Biochem Biophys Res Commun 477: 737-742, 2016.

24. An H, Kim JY, Oh E, Lee N, Cho Y and Seo JH: Salinomycin promotes anoikis and decreases the $\mathrm{CD} 44^{+} / \mathrm{CD} 24^{-}$stem-like population via inhibition of STAT3 activation in MDA-MB-231 cells. PLoS One 10: e0141919, 2015.

25. Krotneva SP, Coffeng LE, Noma M, Zouré HG, Bakoné L, Amazigo UV, de Vlas SJ and Stolk WA: African Program for Onchocerciasis Control 1995-2010: Impact of annual ivermectin mass treatment on off-target infectious diseases. PLoS Negl Trop Dis 9: e0004051, 2015.

26. Yoon YJ, Kim ES, Hwang YS and Choi CY: Avermectin: biochemical and molecular basis of its biosynthesis and regulation. Appl Microbiol Biotechnol 63: 626-634, 2004.

27. Barragry TB: A review of the pharmacology and clinical uses of ivermectin. Can Vet J 28: 512-517, 1987.

28. Sharmeen S, Skrtic M, Sukhai MA, Hurren R, Gronda M, Wang X, Fonseca SB, Sun H, Wood TE, Ward R, et al: The antiparasitic agent ivermectin induces chloride-dependent membrane hyperpolarization and cell death in leukemia cells. Blood 116: 3593-3603, 2010.

29. Liu Y, Fang S, Sun Q and Liu B: Anthelmintic drug ivermectin inhibits angiogenesis, growth and survival of glioblastoma through inducing mitochondrial dysfunction and oxidative stress. Biochem Biophys Res Comun 480: 415-421, 2016.

30. Dou Q, Chen HN, Wang K, Yuan K, Lei Y, Li K, Lan J, Chen Y, Huang Z, Xie N, et al: Ivermectin induces cytostatic autophagy by blocking the PAK1/Akt axis in breast cancer. Cancer Res 76: 4457-4469, 2016

31. Draganov D, Gopalakrishna-Pillai S, Chen YR, Zuckerman N, Moeller S, Wang C, Ann D and Lee PP: Modulation of P2X4/P2X7/Pannexin-1 sensitivity to extracellular ATP via ivermectin induces a non-apoptotic and inflammatory form of cancer cell death. Sci Rep 5: 16222, 2015.

32. Mosin VA, Krugliak EB, Sterlina TS, Korystov IuN, Shaposhnikova VV, Narimanov AA, Kublik LN, Levitman MKh, Viktorov AV and Driniaev VA: Cytotoxic and cytostatic effect of avermectines on tumor cells in vitro. Antibiot Khimioter 45: 10-14, 2000.

33. Melotti A, Mas C, Kuciak M, Lorente-Trigos A, Borges I and Ruiz Altaba A: The river blindness drug ivermectin and related macrocyclic lactones inhibit WNT-TCF pathway responses in human cancer. EMBO Mol Med 6: 1263-1278, 2014.

34. Kwon YJ, Petrie K, Leibovitch BA, Zeng L, Mezei M, Howell L, Gil V, Christova R, Bansal N, Yang S, et al: Selective inhibition of SIN3 corepressor with avermectins as a novel therapeutic strategy in triple-negative breast cancer. Mol Cancer Ther 14: 1824-1836, 2015. 